\title{
Governando a China: a quarta geração de dirigentes assume o controle da modernização
}

\section{AMAURY PORTO DE OLIVEIRA*}

A economia chinesa encetou um salto qualitativo que poderá levá-la, dentro de vinte a trinta anos, ao estágio de economia de dimensão continental, solidamente integrada sobre moderna infra-estrutura de comunicações e transportes. Para administrar esse salto, o Partido Comunista Chinês (PCC) remodelou, no XVI Congresso (2002), suas instâncias superiores: Comitê Central (CC) e Bureau Político (BP). O Comitê Permanente (CP) do BP, que é o efetivo governo da China, foi totalmente renovado. Sua composição foi ampliada de sete para nove membros e, das personalidades que formavam o velho comitê, somente Hu Jintao concorreu à reeleição. Reeleito, foi incontinente designado Secretário-Geral do PCC. Na prática chinesa, modificações na cúpula dirigente, aprovadas num congresso do PCC, são reproduzidas na cúpula do governo, quando se reúne no ano seguinte a Assembléia Nacional do Povo, que é o Legislativo do regime. Isso ocorreu em março de 2002, sendo de destacar as substituições: de Jiang Zemin por Hu Jintao (Chefe do Estado); de Li Peng por Wu Bangguo (Presidente da ANP); de Zhu Rongji por Wen Jiabao (Primeiro Ministro).

Hu Jintao vem sendo reiteradamente apresentado como "o núcleo da Quarta Geração”. A referência, aí, é a uma categoria sociológica estudada por toda uma gama de cientistas sociais e que, no caso chinês, começou a ser usada para descrever a coorte de dirigentes, com visão do mundo grandemente coincidente, a quem toca governar o país durante um certo período. Não pretendo envolverme com os aspectos teóricos que cercam o conceito. Procurarei, apenas, verificar como ele está servindo para nortear a transição da China para o século XXI ${ }^{1}$.

Cumpre, contudo, salientar a natureza elitista da "geração", enquanto forma de governo. Os governantes que compõem a categoria saem das elites dos respectivos regimes. Na China², eles precisam ter galgado ao CC do PCC, que é a instituição-chave da república. Para ali converge a nata dos dois corpos militantes que fizeram e continuam a sustentar a Revolução Chinesa: o PCC e o ELP (Exército

\footnotetext{
Rev. Bras. Polít. Int. 46 (1): 138-160 [2003]

* Embaixador aposentado. Membro do Instituto de Estudos Avançados da Universidade de São Paulo. Cobre a Ásia, no Grupo de Análise da Conjuntura Internacional da USP.
} 
de Libertação Popular). Na fase heróica do maoísmo, o desempenho na luta revolucionária e a firmeza ideológica eram as grandes credenciais para a ascensão ao CC. Com a remodelação do regime promovida por Deng Xiaoping, passaram a ser favorecidos os “engenheiros vermelhos", militantes convictos e com formação universitária. O primeiro CC da era dengista, eleito no XII Congresso (1982), é considerado um divisor de águas nessa tendência em favor dos tecnocratas, que na China se definem como alguém formado numa disciplina técnica, ocupando na administração funções relacionadas com a sua especialidade. Distribuem-se eles por todas as avenidas e travessas do regime, como os responsáveis diretos pelo funcionamento do regime. Na altura do XV CC (1997), já era impressionante o avanço dos tecnocratas na cúpula do partido: mais da metade dos trezentos e quarenta e quatro membros do CC; dezoito dos vinte e quatro membros do BP; todos os sete membros do Comitê Permanente ${ }^{3}$.

Paralelamente ao aparelho do partido, o estamento militar é outra sementeira de profissionais com educação terciária a alimentar os efetivos do CC. Uma das Quatro Modernizações postas em marcha em 1979 tem cuidado da profissionalização permanente das Forças Armadas chinesas, mas as exigências de um domínio aprofundado das técnicas relacionadas com a defesa nacional não vêm afastando os militares de preocupações políticas. Os professores americanos Li Cheng e Lynn White realizaram pesquisa, muito citada, sobre o fluxo de militares para o CC do PCC ${ }^{4}$, focalizando o comitê eleito no XIV Congresso (1992). Dos cinqüenta e cinco membros plenos então chegados ao CC, dezessete vieram do exército, a eles se juntando sete, dentre vinte e oito membros suplentes que passaram a plenos na ocasião. Contando os militares que já estavam no CC, havia agora quarenta e seis deles. Desses, 67\% eram diplomados de instituições de ensino superior, em geral academias militares. Mais de 30\% dos oficiais no XIV CC haviam exercido cargos de direção em academias ou escolas técnicas militares, o que possibilitava postular que, a exemplo do que vinha acontecendo no mundo civil, laços de coleguismos começavam a sobrepor-se a outros vínculos, entre os militares. Durante mais de quatro décadas, a relação comandante-comandado fora a principal determinante das lealdades no seio do ELP. Tomavam agora a dianteira os velhos laços escolares.

Personalidade que teve muito a ver com o florescimento da tecnocracia chinesa foi Jiang Nanxiang, um colaborador de Mao Zedong de quem foi Ministro da Educação. Entre 1952 e 1966, Jiang presidiu a Universidade Qinghua, de Pequim, fundada em 1911 por educadores americanos. Com o objetivo de preparar estudantes amigos para irem fazer cursos de pós-graduação nos Estados Unidos, aqueles educadores criaram a universidade com dinheiro proveniente da "Indenização Boxer", o tributo monetário que a China estava sendo obrigada a pagar a um grupo de potências ocidentais, a título de "reparação” por danos a elas infringidos durante a Rebelião dos Boxers (1900). Com o tempo, Qinghua foi 
absorvida pela realidade chinesa, vindo a ser por exemplo uma arena de lutas durante a Revolução Cultural. Durante o seu mandato, Jiang Nanxiang criou um Sistema dos Conselheiros Políticos (SCP), para o qual eram recrutados alunos de todos os níveis com bom desempenho político (prioritariamente) e acadêmico. Eram eles estimulados a permanecer na Universidade por mais um ano, após a conclusão dos respectivos cursos, “a fim de aprimorarem suas habilitações”. Jiang foi assim criando uma rede de formandos, que ele via como celeiro de futuros dirigentes. E com efeito, na fase modernizadora impulsionada por Deng Xiaoping, foi possível detectar a presença em altos cargos da república de membros da rede tecida por Jiang Nanxiang. Membros de relevo do que hoje se diz "a máfia de Qinghua” são Zhu Rongji e Hu Jintao5.

Jiang Nanxiang esteve afastado de Qinghua durante os dez anos da Revolução Cultural e só readquiriu influência após a derrota dos radicais, num processo ligado de perto à reabilitação de Deng Xiaoping. Entre os primeiros atos de Deng, após retornar ao poder em 1978, esteve a convocação de uma Conferência Nacional de Ciência, para cuja organização ele chamou Jiang Nanxiang. Jiang foi o secretário-geral do evento, assumindo depois as funções de Vice-Presidente da Comissão Estatal de Ciência e Tecnologia. Deng Xiaoping por sua vez, ao praticamente inaugurar sua era com iniciativa dedicada ao trabalho científico, tornou patente a determinação de atribuir à ciência e tecnologia (C\&T) o papel de base das três outras "modernizações”, com cuja promoção se comprometera. Isso foi-se tornando mais claro à medida que eram adotadas políticas destinadas a reestruturar a comunidade científica, dizimada e desmoralizada pela Revolução Cultural, que proclamara a necessidade de os intelectuais se adaptarem à “visão proletária do mundo”. Deng Xiaoping cuidou de elevar o estatuto dos cientistas enquanto grupo social, afastando da chefia de instituições científicas "generalistas" do partido, em favor de profissionais das áreas correspondentes. E formulou, ao ensejo da Conferência de 1978, duas importantes revisões ideológicas. Classificou as atividades de C\&T entre as "forças de produção", e não como parte da "superestrutura"; valia dizer: atividades nem burguesas nem proletárias. Corolário dessa redefinição foi a aceitação dos cientistas e intelectuais como "partes da própria classe operária”.

Não disporei de espaço para acompanhar a formulação e implementação, ao longo dos anos 1980 e 1990 do século passado, das políticas de reestruturação da comunidade científica e tecnológica da China. Vou ter de recorrer ao julgamento de um abalizado especialista que, ele sim, acompanhou o assunto de forma sistemática e bem informada: o Professor Richard P. Suttmeier, da Universidade de Oregon (Estados Unidos). Num artigo escrito em colaboração com Cong Cao, pesquisador do Centro de Estudos sobre a Ásia e o Pacífico (Honolulu), Suttmeier pôde diagnosticar, em 1999: “A China fará face aos desafios do século XXI, tendo ao seu dispor uma substancial comunidade científica, de qualificação variada mas 
crescentemente capaz. Nas duas últimas décadas, passou ela por abrangentes reformas institucionais e mudanças políticas, com o objetivo precípuo de torná-la mais socialmente expressiva, economicamente confiável e apta a competir na busca da excelência na pesquisa e na inovação tecnológica. As políticas reformistas proporcionaram compensações, materialmente expressivas e simbolicamente valiosas, às instituições e indivíduos que foram julgados os mais brilhantes e os melhores. De tudo resultou que o elitismo na ciência veio a adquirir, na última década, um nível de aceitação desconhecido desde o começo dos anos 1960”.

Cao e Suttmeier recorrem à expressão americana "banco de cientistas" para designar o estamento em que se vem agregando uma elite de cientistas, recrutados pela Academia Chinesa de Ciência (ACC) e pela Academia Chinesa de Engenheiros (ACE). Efetua-se tal recrutamento segundo o sistema dito yuanshi, que além de premiar cientistas e engenheiros por suas realizações individuais, vai formando lideranças aptas a darem assistência profissional aos dirigentes políticos, com os quais são estimulados a manter um relacionamento próximo, mas autônomo, nas questões nacionais que envolvam aspectos de C\&T. A institucionalização do sistema yuanshi enfrentou muita oposição, estabilizando-se partir de 1994, quando a ACE foi criada como entidade distinta da ACC. A eleição para esta ou aquela academia processa-se hoje de maneira semelhante às eleições para a National Association of Science, dos Estados Unidos, ou a British Royal Society. Em 1997, o processo eleitoral foi inclusive modificado para dificultar intervenções do PCC na seleção dos membros das academias.

Na perspectiva deste estudo, não vem ao caso avaliar o efeito do sistema yuanshi sobre a qualidade da ciência na China. O que está em foco é a sucessão das “gerações” de dirigentes responsáveis pela modernização do país, tratandose então de verificar como a nata de especialistas produzida pela ACC e ACE tem-se entrosado com esse processo. Será preciso, antes de mais nada, distinguir entre o "banco de cientistas" e a massa de tecnocratas que povoam os canais administrativos da China. Cao e Suttmeier levantaram boa informação sobre os primeiros, acentuando que as oportunidades de ascensão para os cientistas de elite deixou de depender da lealdade política. A filiação ao PCC não é a condição para carreiras científicas bem sucedidas, funcionando a contrário como honraria oferecida a cientistas de valor. As pesquisas mostraram que, entre 1955 e 1997, foi maior o número de cientistas não membros do PCC aceitos na ACC, do que o de membros da ACC que se filiaram ao PCC. Galardão muito usado é a designação de cientistas como deputados ao Congresso Nacional do Povo ou à Conferência Consultiva Política do Povo Chinês, entidades sem real poder político mas de grande prestígio. De todo modo, sempre há um pequeno número de cientistas com atuação partidária, no plano central ou no provincial. No XV Congresso do PCC (1997), por exemplo, cinco acadêmicos da ACC foram eleitos para o CC do partido, na qualidade de membros-suplentes. E com ou sem filiação partidária, os membros 
da ACC vêm cada vez mais prestando assistência profissional aos dirigentes, em questões que vão do ensino da biologia no curso ginasial a grandes projetos de engenharia como a construção de hidrelétricas.

Deng Xiaoping já estava com setenta e quatro anos ao assumir a liderança suprema da China. Tinha consciência de como era curto o tempo para a tarefa, que lhe parecia essencial, de deslocar o regime da tradicional luta de classes para uma trajetória de desenvolvimento econômico e tecnológico. A revolução comunista já fora feita na China. Tratava-se agora de erigir o PCC na promoção e garantia da construção de uma sociedade socialista plenamente integrada na modernidade em mutação. Deng vivera e trabalhara na França dos dezesseis aos vinte e um anos, no seu pleno período formativo. Ligou-se de longe ao nascente movimento comunista chinês, em contato direto com a agitação dos operários franceses. Na França, Deng firmou laços de amizade e identificação intelectual com Chu En-lai, seis anos mais velho do que ele, mas companheiro de lutas nas décadas em que os dois foram ascendendo ao topo do PCC. Unia-os a convicção, nascida na vivência de ambos no exterior, de que a China só superaria o atraso trazido por um século de colonialismo, se se abrisse para o mundo, disposta a aprender com o mundo. Chu En-lai foi o idealizador das "Quatro Modernizações”, transformadas em programa de governo por Deng (1978), com a determinação adicional de abertura da economia chinesa para o mercado internacional.

Quando Deng Xiaoping voltou ao centro do poder, após a morte de Mao Zedong e o fim da Revolução Cultural, encontrou a cúpula do PCC enleada no que se chamava a norma dos "dois o quê quer quê": diante de qualquer problema, valia o quê quer que Mao tivesse dito ou feito. Deng insurgiu-se contra essa submissão à autoridade e conduziu sua própria ascensão à liderança do partido, brandindo o argumento de que "a prática é o único critério da verdade”. Transformou essa asserção numa completa teoria da modernização, exposta com segurança em reuniões do partido, em 1978 e 1979. A visão pragmática do mundo, característica central do pensamento dengista, tem desde então marcado todo o extraordinário reerguimento da China.

No XII Congresso do PCC (1982), Deng procurou preparar o partido e o governo para a boa implementação da abertura ao exterior e as "Quatro Modernizações” (da agricultura, da indústria, das forças armadas e das atividades de ciência e tecnologia), fixando-lhes para os anos 1980 uma agenda em quatro pontos: (1) reestruturar a administração e a economia; (2) construir uma civilização socialista, cultural e ideologicamente avançada; (3) coibir com firmeza atividades criminosas; e (4) corrigir o estilo de trabalho do partido. Este último ponto foi exigindo a substituição maciça dos velhos quadros, em geral pouco educados, por jovens crescentemente profissionalizados. Também a institucionalização gradual do serviço partidário, através da adoção de limites de idade e duração dos mandatos nos diversos níveis hierárquicos, inclusive nos escalões superiores. No XIII 
Congresso (1987), Deng deu exemplo quase sem paralelo de coerência com a própria pregação, renunciando voluntariamente à condição de membro do BP e do CC. Com isso, compeliu mais de noventa anciães a também deixarem as duas instâncias. O único maior de oitenta anos a permanecer foi Yang Shangkun, que era o Chefe do Estado e Vice-Presidente da Comissão Militar Central. Deng era o Presidente dessa CMC, e decidiu continuar por algum tempo no cargo, a fim de manter Yang Shangkun sob seu controle.

As reformas postas em marcha por Deng Xiaoping e suas rigorosas medidas de aprimoramento do partido e do governo provocaram não pouca resistência da velha guarda do regime. Dois quadros sucessivamente designados por Deng para sucedê-lo na liderança suprema - Hu Yaobang e Zhao Ziyang - viram-se compelidos a deixar a cena política. As iniciativas do segundo, em particular, despertaram muita polêmica, havendo contribuído para os trágicos acontecimentos de Tiananmen, em maio de 1989. Dois meses depois reunia-se a Quarta Plenária do XIII Comitê Central (os CC são conhecidos pela numeração do Congresso do PCC que os elegeu) e Zhao Ziyang foi destituído de todos os seus postos no partido, como viria a ser depois dos postos no governo. Tornou-se urgente a escolha de um novo Secretário-Geral, vindo a ser eleito Jiang Zemin, o secretário do partido em Xangai, onde se destacara pela maneira firme, mas não sangrenta, como soubera controlar manifestações contra o regime do tipo das ocorridas em Pequim. Deng foi o patrono de Jiang e, determinado a não ver falhar uma terceira escolha de sucessor, cuidou de dar maior substância à figura do novo Secretário-Geral, pondo em relevo sua posição de "núcleo da Terceira Geração de dirigentes”. Na oportunidade, Deng mencionou a si próprio como o núcleo da Segunda Geração e Mao o da primeira.

Essa inesperada alusão a uma seqüência de "gerações" foi simples recurso argumentativo de Deng Xiaoping. Na verdade, ele estava introduzindo ali o modelo, a fim de dar consistência e legitimidade ao mandato de Jiang Zemin. No mesmo espírito, Deng iria passar a Jiang, alguns meses mais tarde, a presidência da CMC, começando a manobrar com vistas à aposentadoria de Yang Shangkun. Isso viria a ser obtido no XIV Congresso (1992), e Jiang Zemin assumiria logo a seguir também a Chefia do Estado.

Jiang crescera numa família de militantes. Perdeu o pai muito cedo e foi adotado por um tio, também falecido antes da vitória comunista, em condições que lhe garantiram ser incluído no rol dos “mártires do partido”. Isso proporcionou ao órfão facilidades para formar-se em engenharia pela prestigiosa Universidade Jiaotong, de Xangai, e ir fazer pós-graduação na União Soviética. Trabalhou, por quase duas décadas, no Primeiro Ministério da Indústria de Construção de Máquinas e, no início dos anos 1980, deslocou-se para o trabalho partidário, alcançando projeção como o Secretário do PCC em Xangai. Na sua trajetória pelos corredores do governo e do partido, foi tecendo ao seu redor uma rede de 
outros tecnocratas, em geral mais jovens do que ele e que o acompanhariam na ascensão à cúpula do regime. A decisão de Deng Xiaoping de colocar Jiang Zemin à frente do partido e do governo foi recebida com ceticismo nos meios políticos de Pequim. Os conservadores do partido, mas também jornalistas e acadêmicos estrangeiros, descreviam Jiang como político sem carisma, desprovido de bases próprias de poder e, de modo geral, incompetente. Num comentário publicado na edição de 3 de junho de 1990, o correspondente do New York Times referia-se à opinião corrente em Pequim de que Jiang Zemin não sobreviveria no poder, “dois anos após a morte de Deng Xiaoping”. Em anos posteriores, Jiang veio revelando aptidões insuspeitadas de paciência, flexibilidade e ardileza política. Mas parece certo dizer que ele não se teria firmado sem o empurrão inicial que lhe deu Deng ${ }^{7}$.

Na virada dos anos 1980 para os 1990, o velho líder estava tendo de enfrentar grandes desafios. O "socialismo real” desmoronava na Europa Oriental, e a velha guarda do PCC usava isso para agitar contra as reformas esposadas por Deng Xiaoping. As potências ocidentais tinham montado um sistema de pressões contra o regime chinês, ao ensejo dos trágicos acontecimentos de Tiananmen. Os capitais de fora escasseavam e a economia doméstica marcava passo, com reflexos negativos sobre a estabilidade social e política. Tudo isso criava conflitos no âmbito do partido, que via aproximar-se o momento de ter de substituir lideranças. Momento de grande tensão nos partidos leninistas que não tinham sabido desenvolver normas processuais para a seleção e instalação de um novo líder supremo. A resposta de Deng a toda essa contrariedade foi recorrrer ao modelo da "geração", como forma de renovação permanente do papel diretor do partido.

Na visão pragmatista de Deng Xiaoping, coortes de dirigentes estruturados num encadeamento de gerações, cada uma com atuação previsível de dez anos, iriam levando adiante, indefinidamente, a tarefa do desenvolvimento e da modernização tecnológica da China. A cada geração cabia adequar a realidade social, econômica e política do país às mutantes exigências domésticas e do quadro internacional. Ao personagem reconhecido como o núcleo de cada geração competiria velar pela compatibilidade organizacional do partido com os ajustamentos introduzidos por sua coorte. Dessa maneira, tornava-se possível antecipar o gradual acúmulo de conquistas concretas, através das quais o PCC legitimaria continuamente sua presença na governança do regime.

A Terceira Geração foi até agora, na China, o único exemplo do gênero com princípio e fim. É inescapável examinar as soluções empiricamente encontradas por ela para a constituição e funcionamento de uma geração, mesmo não se podendo garantir que tais soluções venham a repetir-se nas gerações vindouras. Quando Deng Xiaoping colocou Jiang Zemin no centro dessa primeira experiência, sua maior preocupação foi assegurar uma transição pacífica na liderança do regime, diante da iminência de sua própria partida. No processo, Deng terá percebido a 
validade do modelo para futuras transições e, no XIV Congresso (1992), agenciou a eleição de Hu Jintao, então com quarenta e nove anos, para o CP do BP, já na presunção de que ele pudesse assumir a liderança da Quarta Geração, dez anos mais tarde. Hu era membro do CC desde 1982, mas não chegara a servir no BP. Não obstante, Deng optou por ele numa lista de três candidatos para o Comitê Permanente, tendo em vista tanto os méritos já acumulados por Hu quanto a conveniência de obter o apoio, para seus planos de institucionalização da vida partidária, de um grupo liderado pelo veterano Chen Yun do qual era membro de destaque outro veterano, Song Ping, padrinho político de Hu Jintao ${ }^{8}$.

A história pessoal e a ascensão política de $\mathrm{Hu} \mathrm{Jitao}^{9}$ são exemplos perfeitos da teoria das “duas linhas”, elaborada por Mao Zedong, nos anos 1960, para definir o caminho a ser seguido por eventuais aspirantes à liderança do regime chinês. A teoria prevê que um aspirante deve dedicar-se ao longo dos anos à boa implementação das tarefas diárias do gerenciamento do partido (primeira linha), sob a direção de um membro mais experiente (segunda linha), que é suposto avaliar e orientar as qualidades e capacidades do pupilo. Com o máximo possível de objetividade, havendo no partido normas não escritas que coíbem o nepotismo puro e simples.

Hu Jintao nasceu em 1942 numa cidade do interior, tendo como pai um contador de armazém local. Provavelmente por esforço próprio, foi admitido aos dezessete anos na Universidade Qinghua, onde se formou em engenharia hidroelétrica em 1965, como um dos últimos estudantes a obter grau universitário antes da suspensão dos cursos pela Revolução Cultural, iniciada em 1966. Dois anos antes ele se inscrevera no PCC, e depois de formado permaneceu trabalhando na Universidade, como um conselheiro político segundo o modelo de Jiang Nanxiang. Hu casou-se com uma colega da Universidade e manteve-se à margem dos violentos choques entre facções rivais dos Guardas Vermelhos, no interior da instituição. Quando Mao pôs termos a esses choques, deportando em massa os estudantes para a zona rural, Hu foi enviado para a remota província de Gansu, onde iria trabalhar por mais de uma década em obras hidráulicas e secretariando comitês do partido. Foi em Gansu que Hu chamou a atenção de Song Ping, o poderoso Secretário provincial do PCC, cuja mulher ocupara cargos do partido em Qinghua, quando Hu lá estudara. Song Ping tornou-se seu primeiro padrinho político, responsável pela frutuosa associação de Hu com a Juventude Comunista Chinesa e sua posterior designação para estudar na Escola Central do Partido, onde Hu reencontrou Jiang Nanxiang no cargo de Vice-Presidente da Escola.

Aproximava-se o XII Congresso do PCC (1982), e o Primeiro Ministro da época, Hu Yaobang, procurava jovens quadros para reforçar o CC do partido. Caçadores de talentos foram despachados, e Hu Jintao foi detectado, inclusive pelo fato raro de possuir um diploma universitário, no imediato pós-Revolução 
Cultural. Hu Yaobang tornar-se-ia o segundo padrinho político de Hu Jintao, levando-o consigo em circuitos de inspeção pelo país e terminando por colocá-lo à testa da Liga da Juventude Comunista Chinesa.

Em 1985, Hu Jintao deixou o movimento juvenil para trabalhar diretamente na estrutura central do partido. Foi nomeado Secretário do PCC em Guizhou, a província mais pobre da China, notável também pela forte presença de minorias étnicas. A experiência como secretário de província é julgada fundamental na formação de um quadro do PCC, e a designação de Hu, aos quarenta e três anos, para tal posto deveu-se a Hu Yaobang, que estava testando as aptidões do protegido. Hu permaneceu em Guizhou de 1985 a 1988, quando foi designado para secretariar o partido na Região Autônoma do Tibete. O secretário anterior, um militar, fora demitido por não ter conseguido controlar manifestações violentas de grupos separatistas tibetanos. Hu assumiu em Lhasa com o primeiro secretário do partido de filiação civil. Teve, no entanto, de trabalhar sob a Lei Marcial, coordenando a ação do ELP na contenção da revolta. Sua atuação no episódio ainda não foi escrutinada.

Em 1990, com um diagnóstico de "mal da altura”, Hu obteve licença para tratar-se em Pequim, assim permanecendo durante dois anos, sem cortar o elo com o Tibete. Song Ping estava na capital em posição de comando, e Hu foi chamado para missões de vários tipos, acabando por impressionar Deng Xiaoping, que se tornou seu terceiro padrinho político. Conforme já ficou visto, Deng alçou Hu Jintao, em 1992, ao CP do CC.

A brilhante trajetória profissional de Hu Jintao e a qualidade superior dos seus padrinhos políticos não teriam, talvez, bastado para sagrá-lo como "o sucessor" do líder supremo, se ele próprio não houvesse cuidado de bem administrar suas oportunidades. Afinal, é de imaginar que outros aspirantes estivessem também acumulando credenciais. Basta citar o caso de Zeng Qinghong ${ }^{10}$, o assessor mais diretamente ligado a Jiang Zemin, que já patrocinara sua eleição para o BP e, em novembro de 2002, assegurou sua entrada no respectivo comitê permanente. A imprensa ocidental especulou durante meses sobre a eventualidade de Jiang Zemin frustrar a ascensão final de Hu Jintao, fazendo de Zeng Qinghong o SecretárioGeral do partido. Zeng é um lídimo representante da categoria dita dos "principezinhos". Filhos e filhas de líderes do regime, que crescem em contato com outro figurões, usufruindo de facilidades abertas à elite partidária e governamental. Têm suas carreiras facilitadas, o que não quer dizer que não possam ser efetivamente capazes e preparados. Zeng Qinghong, filho de dois militantes de relevo dos começos da RPC, é um cientista especializado em foguetes, cooptado depois para o trabalho partidário. Adquiriu fama de político habilidoso e maquiavélico, arquiteto de muitos dos triunfos de Jiang Zemin nas escaramuças de cúpula. É citado também como um dos principais formuladores da política externa da China, em particular diante dos Estados Unidos. Aparentemente, está fazendo boa liga 
com Hu Jintao, no CP do BP.

Nos dois anos passados em Pequim no início dos anos 1990, licenciado das obrigações do Tibete, Hu Jintao assessorou Song Ping no monitoramento, treinamento e realocação de membros seniores do partido, além da supervisão de entidades ancilares como a Liga da Juventude Comunista e a Federação Sindical. Song Ping e outros veteranos deixaram o CP do BP no XIV Congresso (1992), abrindo vaga para a eleição de quadros mais novos como Zhu Rongji e o próprio Hu Jintao. Este recebeu o acompanhamento dos assuntos do partido entre suas atribuições, vindo a desempenhar diretamente as tarefas em que antes secundara Song Ping. Em 1993, Hu foi designado para presidir a Escola Central do partido, instituição que recebe anualmente levas de quadros do "terceiro escalão", selecionados por autoridades provinciais e ministeriais para um treinamento intensivo indispensável para promoções futuras. Hu revelou-se presidente dedicado da Escola, dando aulas pessoalmente e desenvolvendo estreito relacionamento com muitos alunos, com os quais seguiu se correspondendo após o retorno deles para suas várias regiões.

Ainda na condição de membro do comitê permanente, Hu tornou-se responsável pelos assuntos do Noroeste da China, com a obrigação de viagens periódicas à região, a fim de avaliar os líderes locais e recomendar seu aproveitamento futuro. Por toda parte, Hu encontrava colegas e subordinados do seu tempo na direção da Liga da Juventude, e via surgirem novas oportunidades para ampliar sua rede de influência. Mas, para aumentar suas chances de suceder a Jiang Zemin, como o núcleo da Quarta Geração, Hu Jintao ainda precisava obter a luz verde dos militares e o apoio decidido do próprio Jiang. Esse apoio começou a consolidar-se em 1995, quando Hu colocou-se firmemente ao lado do Secretário-Geral, num dos embates decisivos da afirmação de Jiang Zemin como o núcleo da Terceira Geração: a demolição política de Chen Xitong, membro do BP e Prefeito de Pequim. À frente de um verdadeiro império de corrupção na capital, Chen Xitong parecia estar tramando um ataque contra Jiang, que reagiu abrindo rigorosa devassa contra Chen. Chamado a ocupar-se do assunto, Hu Jintao conduziu com eficácia as investigações e as medidas administrativas que encerraram o episódio.

Com o beneplácito de Jiang Zemin, Hu Jintao iria ser nomeado VicePresidente da República na sessão de março de 1998 da Assembléia Nacional do Povo. Aos cinqüenta e seis anos, o mais novo Vice-Presidente da história da RPC, Hu recebeu imediatamente o espinhoso encargo de supervisionar a liquidação de todas as operações comerciais e industriais do ELP, em implementação de medida adotada na mesma sessão da ANP. Junto com Zhu Rongji, companheiro de CP que acabara de ser empossado como Primeiro Ministro, Hu Jintao deu conta da tarefa com a característica eficiência e presteza, sem provocar a ira dos generais.

Durante os longos anos de luta contra os japoneses e os nacionalistas do 
Kuomintang, os grupos armados embriões do ELP tinham tido de prover à própria subsistência, sem exações sobre as populações camponesas que lhes davam guarida. A auto-suficiência tornou-se a norma, num tipo de solução que levaria à edificação, na futura República, de um complexo industrial-comercial para a produção e distribuição de armas e tudo mais de que precisassem as Forças Armadas. De Mao Zedong a Deng Xiaoping, os dirigentes foram tolerando a existência desse império, de que se dizia abarcar vinte mil empresas por todo o país, com lucros anuais da ordem de 600 milhões de dólares. Um contexto propício a abusos e corrupção, que os homens da Terceira Geração se sentiram livres para coibir, após a morte de Deng Xioping (fevereiro de 1997) e aproveitando a movimentação associada ao XV Congresso (1997). Congresso esse visto como o limite extremo da influência dos velhos revolucionários da Primeira e Segunda Gerações.

A maneira correta como Hu Jintao soube aplicar o princípio maoísta de que "o partido comanda o fuzil sem jamais deixar que o fuzil tome o comando do partido” abriu caminho para sua nomeação em 1999, sem reação negativa dos militares, para o cargo de Vice-Presidente da Comissão Militar Central. A chefia dessa CMC - recorde-se - fora passada por Deng Xiaoping a Jiang Zemin, em 1989, como a peça final de edificação da liderança de Jiang. Ele tivera de trabalhar com prudência e finura, durante alguns anos, até ser aceito pelos militares como o presidente incontestável da CMC, posto que traz consigo o Comando-em-Chefe das Forças Armadas. Jiang chegou inclusive a ser visto pelos militares como um deles, na medida em que se tornou o paladino das diversas reivindicações materiais da corporação. Sob sua égide, foram feitas três remodelações da CMC e de alguns departamentos centrais do ELP, de tal modo que o Alto-Comando veio a estar repleto de oficiais na faixa etária de Jiang Zemin ${ }^{11}$.

Hu Jintao tomou assento no segundo posto da CMC, em condições bem mais favoráveis do que as enfrentadas dez anos antes por Jiang Zemin, ao assumir o primeiro posto. Segundo relatos de imprensa, um escritório foi instalado para $\mathrm{Hu}$ no edifício central do ELP e um oficial de ligação de alta-patente foi designado para servi-lo. Hu participa de reuniões-chaves do estabelecimento militar, inspeciona regiões e é mantido regularmente informado dos principais desenvolvimentos. Tendo sido já confirmado como Secretário-Geral do partido e Presidente da República, não parece haver dúvida de que Hu Jintao assumirá, no devido tempo, a chefia da CMC.

Examinando como funcionou a Terceira e vai-se estruturando a Quarta, vêem-se as gerações políticas, na China, com uma face pública que é o Comitê Permanente do Bureau Político. Nele está contido o núcleo da geração, ou seja, o Secretário-Geral do partido e Presidente efetivo ou potencial da Comissão Militar Central. Cada membro do CP é responsável por instituição como a ANP ou algum setor da vida político-econômica, à frente de rede de aliados e comandados tecida ao longo das respectivas carreiras. Por trás, portanto, da face visível da geração 
há algumas dezenas de quadros de segundo e terceiro escalões, acumulando pontos no CC ou no BP, na esperança de chegar ao CP. A triagem para tal ascensão processa-se segundo o modelo das “duas linhas”, tão brilhantemente seguido por Hu Jintao. É processo lento, tornando-se possível identificar com antecedência os prováveis vitoriosos na corrida para o CP. Em artigo publicado no número de janeiro de 2001 da revista australiana The China Journal, o professor taiwanês Parris H. Chang deu belo exemplo disso, fornecendo com precisão os nomes dos seis dirigentes que deveriam asceder ao CP no XVI Congresso, em torno do inamovível Hu Jintao. Só faltaram os dois dirigentes que tiveram de ser buscados à última hora para preencher as vagas resultantes da ampliação do CP para nove membros. É interessante verificar que a equipe eleita em novembro de 2002 só inclui um membro mais novo (um ano de diferença) do que Hu Jintao, ou seja, o atual CP não inclui dirigente habilitado a reivindicar a condição de núcleo da Quinta Geração, quando chegar a hora de empossá-la, dentro de dez anos em princípio. O assunto terá de ser dirimido, presumivelmente, no XVII Congresso, em 2007.

A esse propósito, cabe também notar que a composição de novo CP é, majoritariamente (seis em nove), de aliados de Jiang Zemin. Há um membro ligado ao setor de segurança, que foi patrocinado pelo cessante Li Peng, e outro que era o vice de Zhu Rongji e já o sucedeu como Primeiro Ministro. Hu Jintao manteve sua posição, mas aparentemente não trouxe ninguém de seu para o CP. Isso reforça a tese de que o período até o XVII Congresso será tomado por um jogo de cristas, no qual Hu Jintao procurará afirmar sua autoridade e projetá-la na definição da Quinta Geração. Companheiro de CP que parece afinar-se com Hu é o Primeiro Ministro, Wen Jiabao. Wen foi um dos preteridos por Hu, na já citada lista tríplice submetida a Deng Xiaoping em 1992, para ingresso no CP. Continuou, porém, sua ascensão, tendo tido Song Ping como seu principal padrinho político. Assessorou de perto Zhao Ziyang, mas escapou às punições partidárias que caíram sobre esse ex-Secretário-Geral, em função dos trágicos acontecimentos de Tiananmen. Geólogo de formação, Wen Jiabao teve uma longa trajetória por zonas rurais, mas chefiou também, durante sete anos, o Escritório de Assuntos Gerais do PCC, encarregado de preparar a agenda das reuniões partidárias e proceder à distribuição interna de documentos. Ganhou fama como perito em agricultura e meio-ambiente, tendo sido chamado por Zhu Rongji, em 1998, para um dos postos de Vice-Primeiro Ministro, responsável pela modernização da agricultura e a reforma financeira. Sob sua direção, importantes passos foram dados no sentido da criação de uma infra-estrutura financeira mais sólida, na China, mas seu melhor desempenho foi no setor da economia rural, em particular na concessão de maiores direitos aos camponeses sobre as terras que cultivam. A expectativa é que Hu e Wen levem o partido a dar maior peso às lideranças rurais e façam avançar a democracia no campo, reforçando por exemplo as eleições no nível de aldeias e municípios ${ }^{12}$. 
Apesar das medidas regulamentadoras introduzidas nos anos 1990, as relações políticas na cúpula do regime chinês ainda se equacionam em termos de homens, mais do que princípios. Mas como os líderes já não podem invocar serviços como na fase heróica da Revolução, suas posições de liderança tendem a apoiarse cada vez mais numa legalidade institucional, construída sobre consensos e compromissos no plano da elite partidária. No mesmo passo, cuidam os dirigentes de legitimar a hegemonia do PCC, fazendo valer sua condição de promotor e garantia do robustecimento da economia nacional e conseqüente melhoria da vida material da população. Isso caminhará por etapas, num encadeamento de gerações, cada uma delas levando até certo ponto o processo de adequação do regime às cambiantes realidades do país e do mundo. Jiang Zemin captou bem o pensamento de Deng Xiaoping a esse respeito, assim também quanto ao dever dos núcleos de geração de assegurarem a compatibilidade organizacional do partido com os ajustamentos característicos de cada etapa. Sob impulsão de Jiang, o aparelho administrativo central foi consideravelmente descentralizado, no partido e no governo. No tocante ao pessoal, estimularam-se a criação de carreiras de Estado e o aperfeiçoamento (mais jovens, mais educados e mais profissionais) dos quadros e funcionários. Passos largos foram dados na profissionalização das Forças Armadas.

No XV Congresso (1997), com a aposentadoria de Qiao Shi e a transferência para a chefia do Legislativo de Li Peng, Zhu Rongji assumiu as funções de Primeiro Ministro. Ele tinha trabalhado com Jiang Zemin em Xangai, onde tinham aprendido a respeitar-se mutuamente. Zhu não podia, contudo, ser considerado membro da "máfia de Xangai”, obediente a Jiang; seu círculo de apoio é a rede de tecnocratas da Universidade Qinghua, onde ele é decano de uma Faculdade. De todo modo, Jiang Zemin e Zhu Rongji tornaram-se no final dos anos 1990 as figuras-chaves da Terceira Geração, atuando em tandem no ajustamento da China às exigências de um mundo que se globalizava.

Em maio de 1997, como preparação para o XV Congresso, Jiang desenvolveu na Escola Central do PCC uma argumentação cerrada em prol da ampliação do setor privado na economia chinesa. Em julho, Zhu efetuou circuito de doze dias pelo Cinturão Industrial do Nordeste, trocando em miúdo as teses de Jiang para os diretores das encalacradas empresas estatais. Na seqüência, o Congresso de setembro redefiniria os limites da propriedade do Estado na China, de maneira a incluir na economia socialista as sociedades por ação e as associações do Estado com investidores privados ${ }^{13}$. Em março seguinte, ao tomar posse como Primeiro Ministro, Zhu Rongji submeteu à ANP um abrangente e ousado programa de reforma das estatais e de reformulação das relações com investidores estrangeiros. Propugnou também pelo ingresso da China na OMC. Era um programa que só poderia ser bem sucedido se as medidas propostas fossem promovidas 
entrelaçadamente, com a reforma das estatais servindo de fulcro. E Zhu achava que a pressão estrangeira pelo ingresso da China na OMC haveria de reduzir as resistências domésticas à reforma das estatais.

A implementação do programa de Zhu enfrentou resistências bem maiores do que ele esperava, dando margem inclusive a manifestações de operários e camponeses contra o aumento do desemprego. As perspectivas pareciam melhores no plano externo, com os sinais recebidos do Presidente americano, de boa disposição para com a entrada da China na OMC. Em abril de 1999, Zhu viajou a Washington levando uma generosa concordância da China com as regras da OMC, por cuja aprovação ele e Jiang tinham tido de lutar, numa reunião do BP. Bill Clinton voltou atrás, no entanto, quando Zhu se apresentou em Washington. De volta a casa, Zhu teve de enfrentar meses difíceis, só perseverando no cargo graças ao apoio recebido de Jiang Zemin. Ele retomou a busca de um acordo com os Estados Unidos na questão da OMC, trabalhando agora junto a corporações americanas com seu fascínio pelo mercado chinês. Em começos de novembro de 1999, a Representante para o Comércio, Charlene Barshevsky, viajou a Pequim e, no dia 15 desse mês, foi assinado o acordo sino-americano que abriu à China as portas da $\mathrm{OMC}^{14}$.

Vitoriosos na questão da OMC, Jiang e Zhu puderam lançar-se a uma verdadeira releitura do legado teórico de Deng Xiaoping. Em fevereiro de 2000, num discurso em Cantão, Jiang delineou algumas idéias para a reatualização do PCC na perspectiva do século XXI e da globalização. Um passo adiante era dado no tocante à formulação de Deng, que incluíra os intelectuais na classe operária, acentuando não deixarem eles de ser trabalhadores pelo fato de trabalharem com a inteligência. Jiang rompia agora com a primordialidade da classe operária, identificando o partido com todos os elementos mais progressistas da sociedade. As teses de Jiang Zemin foram rotuladas de “As Três Representações” e teóricos do partido foram chamados para dar maior consistência a elas. Hu Jintao teve participação ativa na consolidação e difusão do pensamento de Jiang Zemin, e o próprio Jiang desdobrou suas idéias num importante discurso (01.07.01) comemorativo dos 80 anos da fundação do PCC. Esse discurso tornou-se conhecido como “o discurso de $1^{\circ}$ de julho de Jiang”, numa referência ao histórico discurso pronunciado por Deng Xiaoping na mesma efeméride, dez anos antes.

Todo esse esforço de reelaboração teórica, no quadro do qual Jiang Zemin chegou a contestar algumas noções da teoria marxista do valor, a pedra-angular das economias comunistas, afluiu para o XVI Congresso (2002), quando se procedeu à revisão da Carta do PCC. Enquanto a Carta anterior estatuía no Preâmbulo: “O Partido Comunista Chinês é a vanguarda da classe operária chinesa; o representante leal dos interesses de todas as nacionalidades da China; e a liderança central da empresa socialista na China”, a nova versão do mesmo parágrafo passou a afirmar que o PCC "representa as exigências de desenvolvimento das forças 
avançadas de produção; a direção progressista da cultura de ponta da China; e os interesses fundamentais da vasta maioria do povo chinês”. Estavam consagradas as “Três Representações”.

A nova abordagem já se expressou na abertura a empresários da filiação ao PCC. Numa reunião plenária em outubro de 2000, o CC já decidira reforçar o peso do setor privado na economia, substituindo por "apoiar e guiar" o compromisso do Estado com esse setor, que na redação aprovada no XV Congresso (1997) limitava-se a "permitir e encorajar". A nova fórmula prenunciava o desmantelamento, antes mesmo de ter sido completada a reforma das empresas estatais, de barreiras políticas à ação dos homens de negócios. Manifestava-se, aí, uma importante característica do gradualismo com que os dirigentes chineses implementam seu programa de reformas. Eles não se limitam a agir pausadamente. Vão também introduzindo elementos inovadores, num sistema em que seguem fortes velhos elementos. Robustecer o setor privado é visto, no caso, como mais importante do que demorar-se na reforma das estatais. Usa-se o avançado para suplantar o atrasado $^{15}$.

Quando afinal se reuniu o XVI Congresso, em novembro de $2002^{16}$, um grupo de empresários de relevo foi incluído entre os mais de dois mil delegados. No discurso inaugural, Jiang Zemin anunciou que o partido pretende dar às companhias privadas condições de funcionamento equivalentes às das estatais, embora devam estas continuar a desempenhar o papel dominante na economia, como de esperar numa economia de cunho socialista. Os dirigentes chineses insistem em que estão construindo um socialismo de mercado, ou seja, uma economia de mercado administrada não por capitalistas e sim pelo partido comunista. Mas dão-se conta, realisticamente, de que o fortalecimento do setor privado começa a ser fundamental para a própria continuidade do controle do PCC sobre a inquietação social. Uma reportagem do Financial Times (06.11.02) revelou, por exemplo, que cerca de metade das novas oportunidades de emprego, naquela época, estavam sendo proporcionadas pelo setor privado, o qual entrava igualmente com parte significativa da arrecadação fiscal do país.

Em 2003, então, a Quarta Geração assumiu a governança da China ${ }^{17}$. Na sua face visível alinham-se nove engenheiros, todos civis. Todos com longo traquejo dos caminhos do partido e folhas-de-serviço repletas de tarefas bem cumpridas, nos mais variados setores da vida político-econômica do país. Não foram escolhidos aleatoriamente e, embora sem passar por algum tipo de votação popular, chegaram aonde estão através de sucessivos credenciamentos por seus pares: ser feito delegado a um Congresso do PCC; sair eleito para o CC; após algum tempo, ser eleito para o grupo seleto do BP; galgar finalmente ao CP. No caminho, vencer uns tantos obstáculos estatutários, como a obrigação de cursar a Escola Central do Partido. Evidentemente, como em qualquer outro país do mundo, relações de 
parentesco ou de clientelismo facilitarão alguns desses acessos, mas o critério do merecimento predomina nas promoções. Não são raros os casos de alto dirigente que enfrenta dificuldades para promover algum assessor seu.

Por trás da face visível da geração alinham-se as redes de influência, no âmbito do BP e do CC, de cada um dos membros do CP. E para lá do partido, cresce desde o início dos anos 1990 uma multidão de representantes de novos setores da elite chinesa, frutos do próprio avanço da modernização e abertura da China. São profissionais liberais, intelectuais de vários tipos, artistas e empresários. Focalizei mais acima os cientistas e engenheiros reunidos na ACC e na ACE, que inclusive já conquistaram assentos no CC. Vale também citar uma reportagem de Business Week (05.06.95), dedicada ao que a revista chamou a "classe de 77". Legiões de homens e mulheres, atualmente na faixa dos quarenta anos de idade, e que foram os mais bem sucedidos dos doze milhões de jovens que em 1977/78, com o término da Revolução Cultural, puderam matricular-se nas melhores universidades chinesas. Eram jovens sedentos de saber, ansiosos por coroar com a teoria as ricas lições práticas que haviam recebido em anos de degredo, trabalhando na base da pirâmide social. Muitos deles foram depois aperfeiçoar-se no Ocidente, e hoje estão no topo dos setores de ponta do país. Precisamente o tipo de pessoas que o PCC procura abarcar sob a fórmula das "Três Representações”, de Jiang Zemin.

A “classe 77” faz papel de paradigma. Muitas outras classes se formaram no meio tempo nas grandes universidades chinesas e vieram adensar a camada de moços e moças que, juntamente com jovens empresários chegados por outros caminhos, mantêm a China entrosada com a sociedade global do conhecimento. Uma pesquisa publicada em três números da Far Eastern Economic Review, no mês de dezembro de 2002, fornece visão estatística de parcela expressiva dessa juventude: os com menos de trinta e cinco anos nas cidades de Xangai, Pequim e Cantão, principais centros comerciais do país. Mais da metade deles é fluente em inglês; $80 \%$ se declaram proficientes no uso de computadores e da internet; quase $100 \%$ possuem telefone celular e mais de $80 \%$ usam cartões de crédito. O estado de espírito desses jovens é de otimismo com relação ao destino da China e de confiança no próprio futuro. Vêem com bons olhos o ingresso do país na OMC. Mantêm-se em dia com o progresso da aparelhagem tecnológica que utilizam; e dão preferência de modo geral aos eletroeletrônicos da produção nacional. A Legend, fabricante de computadores vendidos com sucesso no exterior, controla parcela substancial do mercado doméstico.

O Professor Joseph Fewsmith, da Universidade de Boston, é possivelmente o mais dedicado analista do crescimento e diversificação dos interesses societais na China pós-Deng Xiaoping. Em vários estudos sobre o assunto, Fewsmith coloca o comportamento da Terceira Geração, nos anos 1990, na perspectiva do esforço 
secular da elite chinesa por "modernizar" a China sem sacrificar a especificidade chinesa. Sob a liderança de Jiang Zemin, a Terceira Geração avançou com muita cautela na reforma política, pondo ênfase na separação entre a economia e o governo. Nesse sentido foram as medidas aprovadas no XV Congresso do PCC (1997) e a decisão de buscar o ingresso na OMC. Os anos 1990 foram marcados por vários debates intelectuais, com os integrantes da "classe de 77" e seguintes, esquadrinhando as consequiências do colapso da União Soviética, a marcha da globalização, a profissionalização e internacionalização dos intelectuais, etc. Fewsmith acompanha esses vários debates, chegando à surpreendente conclusão de que os dirigentes chineses vêm-se mostrando mais "liberais" do que a maior parte da intelectualidade do país. O comportamento dos intelectuais chineses em episódios como o do bombardeamento da Embaixada da China em Belgrado ou o do avião espião americano forçado a descer na Ilha de Hainan revela, na verdade, um repúdio ao cosmopolitismo, em favor de um nacionalismo pragmático, que se expressa em termos de patriotismo. A juventude se identifica aí com a promoção, pelos dirigentes posteriores a Deng Xiaoping, de um nacionalismo despojado de idéias abstratas, que inclusive rompeu com a doutrina leninista do combate de classes ao Imperialismo. Nação e Estado se confundem, sob a direção do PCC, que é o condutor do projeto magno de integração da China com tudo que possa haver de mais avançado no globo em matéria de ciência e tecnologia, graças ao livre intercâmbio comercial e cultural com todos os países do mundo. Cuidado sempre tido de manter vivas as “características chinesas”, a maior das quais resulta ser a adesão inarredável à soberania nacional ${ }^{18}$.

Outro autor a tomar em consideração é Manuel Castells, que na sua trilogia sobre a moderna sociedade em rede oferece análise abalizada da problemática chinesa, atualizada até o final de 1998. Castells rejeita a opinião dos que subordinam o desenvolvimento futuro da China à emergência, ali, da democracia, e vêem o poder do PCC fadado a desmoronar, à medida que crescerem as novas classes urbanas e surgir uma sociedade civil mais robusta. Castells afirma que as informações por ele mesmo levantadas na China não embasam tal expectativa. Considera remotas as possibilidades de expansão de uma sociedade civil autônoma e de consolidação da democracia, enquanto o PCC preservar sua unidade e o Estado chinês mostrar-se eficiente na administração dos conflitos entre as diferentes esferas do governo e entre as diferentes províncias, com o ELP servindo de fiel a tudo isso.

Na abertura do novo milênio - continua Castells -, a China terá sem dúvida de enfrentar uma série de problemas difíceis, nenhum deles relacionado com a democracia, de cuja boa solução dependerá o futuro do país. Castells organiza esses problemas sob quatro títulos, a saber: (1) o êxodo rural maciço provocado pela modernização e privatização da agricultura; (2) tensões criadas entre as províncias pelo desenvolvimento desigual das mesmas e a liberdade que 
lhes deu o governo central de se associarem individualmente com a economia internacional; (3) continuar a desenvolver a economia sem provocar o descontrole do desemprego e o desmantelamento do sistema de segurança; e (4) solidificar a base tecnológica apenas incipiente, a fim de integrar a China na Sociedade do Conhecimento ${ }^{19}$.

Enfrentar os desafios cobertos por essa agenda, num país de nove milhões e meio de quilômetros quadrados com um quinto da população do globo, meteria medo a governantes menos preparados para a tarefa do que os nove homens do comitê de frente da Quarta Geração. Mas além do preparo, o modelo das gerações dá a eles a vantagem de só precisarem, na primeira década do século, lançar os alicerces da economia continental chinesa. Três outras gerações vão ter ainda de ser chamadas até a consolidação, entre 2030 e 2040, de economia com um PIB equivalente ao dos Estados Unidos de hoje. E só lá para meados do século é possível esperar a concretização do postulado "socialismo de mercado". A montagem da infra-estrutura para tudo isso foi iniciada pela Terceira Geração. Em 1993, inspirando-se no modelo americano das Superestradas da Informação, o governo chinês da época instituiu a Infra-estrutura Nacional da Informação para promover as telecomunicações, as tecnologias da informação e a indústria do entretenimento. Grandes passos foram dados nessas diversas frentes, exemplificados pelos cento e vinte milhões de usuários da internet previstos para 2004. Vieram também crescendo as malhas rodoviária e ferroviária. A China entrou no século XXI com mais de trinta mil quilômetros de boas estradas de rodagem e outros tantos já programados, de maneira a atingir, na altura de 2020, uma rede rodoviária só superada pela dos Estados Unidos. No setor ferroviário, planeja-se acrescentar até o final da década sete mil quilômetros de trilhos aos já existentes sessenta e oito mil quilômetros. As estradas-de-ferro foram uma das áreas mais protegidas sob a economia centralmente planificada. Agora, com o ingresso da China na OMC, foi o setor aberto aos capitais estrangeiros: a partir de 2002, investidores de fora puderam participar, minoritariamente, de empresas locais de frete; em 2004 poderão tomar participações majoritárias; e em 2006 serão levantadas todas as restrições ao capital estrangeiro no setor de cargas, continuando fechados os serviços de passageiros.

Em 2001, já nas preliminares para o XVI Congresso do PCC, em 2002, foi lançado o X Plano Qüinqüenal cobrindo ampla gama de objetivos, coincidentes, grosso modo, com os problemas alinhados por Castells. O cerne do plano é a Estratégia para o Desenvolvimento da Região Ocidental da China, uma verdadeira conclamação à “Marcha para o Oeste”. Dois projetos básicos dessa integração continental da economia chinesa já estão tomando corpo. O primeiro é o gigantesco complexo hidroelétrico das Três Gargantas, no Iang Tse, que já começou a produzir eletricidade em meados de 2003. O segundo é a transformação da decrépita e poluída Chungqing na “Chicago da China”. Uma área três vezes maior do que a 
Bélgica, no curso médio do Iang Tse, foi elevada a Municipalidade Autônoma de Chungqing (à semelhança de Pequim, Xangai e Tianjin) e a um custo de 20 bilhões de dólares por ano, durante dez anos, procurará repetir o papel de Chicago na continentalização da economia dos Estados Unidos no século XIX: entroncamento ferroviário de alcance nacional e centro redistribuidor da produção agrícola do Grande Oeste. Para coordenar toda a estratégia de desenvolvimento dessa ampla região foi criado, em 2001, um poderoso comitê de vinte altas autoridades sob a presidência do Primeiro Ministro Zhu Rongji e o Vice-Primeiro Ministro Wen Jiabao de sub-chefe. Wen Jiabao tornou-se agora o responsável máximo pela estratégia de desenvolvimento das regiões ocidentais e, confirmando sua reputação de homem de grande visão nas questões ambientais, passou a defender um ritmo mais lento de desenvolvimento, prestando atenção ao controle da poluição do ar e da água.

Não tem, por exemplo, demonstrado entusiasmo com o faraônico projeto do governo anterior de transferir água do Iang Tse para três outros rios mais ao norte. Esse projeto se prende à questão crucial de que terá de ocupar-se a Quarta Geração: o suprimento de água tratada para uma população em vias de urbanizarse aceleradamente. As estimativas oficiais prevêem duzentos e quarenta milhões de pessoas movendo-se do campo para as cidades, nos próximos vinte anos. A pressão daí resultante e os compromissos já assumidos com a OMC estão forçando o governo a suspender restrições à entrada de firmas estrangeiras no serviço público da água. Em julho de 2003, pela primeira vez na China, uma administração municipal na província de Jiangsu abriu licitação internacional para participação de $70 \%$, durante cinqüenta anos, no tratamento e fornecimento de água para o município.

Wen Jiabao mostrou logo ao que viera, quando seu governo apenas empossado precisou fazer frente à irrupção, que poderia ter sido devastadora, da síndrome respiratória aguda grave (SARS, na sigla inglesa). Usando com rapidez e destemor os recursos de autoritarismo do regime chinês, mas demonstrando a capacidade de enfrentar positivamente os impedimentos políticos e burocráticos responsáveis pela opacidade e ineficiência da reação governamental a situações como a da SARS, Wen Jiabao pôde conter os estragos a ponto de cair sobre a economia chinesa, introduzindo no mesmo passo medidas de aperfeiçoamento do sistema de saúde do país e de adequação das regras internas à prática internacional. A 29 de abril de 2003, Wen efetuou sua primeira viagem ao exterior como Primeiro Ministro, indo reunir-se em Bangcoc com os dez Chefes de Estado e Governo da ANSEA (Associação das Nações do Sudeste Asiático). Medidas concretas para defender a sub-região contra a SARS foram adotadas por unanimidade nessa reunião, que marcou também o aprofundamento do trabalho da China com seus vizinhos sulistas. Em conseqüência, já foi anunciado que a China vai assinar, até o fim de 2003, o Tratado de Amizade e Cooperação que criou a ANSEA, em 1976. 
O tratado é aberto à adesão de países não exatamente do Sudeste Asiático, havendo sido assinado pela Papuásia-Nova Guiné, em 1989.

Em novembro de 2002, numa outra reunião da ANSEA, dessa vez na capital do Camboja, o Primeiro Ministro Zhu Rongji deu impulso à constituição de uma área de livre comércio entre a China e os países do Sudeste Asiático, prevista para começar a funcionar em 2010. Paralelamente, vinha a China se firmando como o sustentáculo da crescente convergência entre as economias do Nordeste Asiático, conforme reconhecido num Livro Branco sobre comércio internacional, publicado pelo governo japonês em junho de 2002. A China substituía o Japão como o novo dínamo de toda a Ásia Oriental, com quase 40\% do PIB da região. Essa centralidade da economia chinesa foi consagrada pela VIII Conferência Internacional sobre o Futuro da Ásia (Tóquio, maio de 2002). Doze países da Ásia-Pacífico debateram ali o tema: “A Emergência da China e o Quadro Regional em Transformação”.

O dinamismo da economia chinesa começa a projetar-se sobre toda a Ásia. Em 2000, Pequim aderiu a um pacto pouco conhecido, o Acordo de Bangcoc, concluído em 1975 sob os auspícios da Comissão Econômica e Social para a Ásia, das Nações Unidas. Membros fundadores foram Índia, Coréia do Sul, Bangladesh, Sri Lanka e Laos, e o propósito era expandir o comércio entre os signatários através de reduções preferenciais de tarifas. A China interessou-se pelo pacto em função do seu ingresso na OMC, passando a trabalhar pela ampliação dos objetivos colimados. Resultado concreto dessa movimentação foi o acordo ChinaÍndia de fevereiro de 2003, estabelecendo reduções tarifárias para cerca de duzentos itens, em favor da Índia na maior parte. Acesso favorecido ao mercado chinês foi também estendido a firmas indianas, numa estratégia que pretende partilhar as conquistas do desenvolvimento chinês com os países em desenvolvimento do continente.

Desde o início das reformas de Deng Xiaoping, a modernização social e econômica da China tem sido conduzida passo a passo com a abertura do país ao mercado internacional. A busca de investimentos estrangeiros, o gradual aperfeiçoamento dos sistemas financeiro e bancário, a maior transparência da ação do Estado, o ingresso na OMC foram todas medidas com vistas à integração da economia continental em construção, no mundo globalizado do século XXI. Que isso vem sendo conseguido fica evidente pelo crescimento dos investimentos estrangeiros: mais de 50 bilhões de dólares em 2002, e pela explosão das exportações. Entre 1985 e 2001, as exportações chinesas se multiplicaram por dez, alcançando 266 bilhões de dólares e permitindo o acúmulo de 300 bilhões de dólares de reservas cambiais. No tocante às exportações, é importante notar a grande diversificação ocorrida, em favor de produtos de alto valor agregado. Itens agrícolas e siderúrgicos, que em 1985 ainda representavam 49\% das exportações chinesas, estão hoje reduzidos a $12 \%$ das mesmas. O aprimoramento da pauta 
exportadora da China é fruto, sobretudo, da intensa e extensa interação da economia chinesa com as redes produtivas globais, num processo mediado pela diáspora chinesa. A China é hoje a quarta economia industrial do mundo, atrás apenas dos Estados Unidos, Japão e Alemanha, mas é também a maior base produtiva de manufaturas do globo. A ação coordenada do governo e empresários chineses, a ser agora continuada pela Quarta Geração, veio montando na China um ambiente manufatureiro de primeira linha, apto a fazer do país um dos beneficiários da globalização.

Agosto de 2003

\section{Notas}

1 Dentre os cientistas sociais que se têm ocupado do problema da geração como categoria política de elite, destacarei Emile Durkheim e Karl Mannheim. Este último, em particular, tem conceitos muito úteis para a análise teórica do caso chinês. Cf. a respeito o artigo do Prof. Li Cheng, do Hamilton College de Nova York: “Jiang Zemin’s Successors: The Rise of the Fourth Generation of Leaders in the PCC” (The China Quarterly, n. 161, March 2000), que foi o texto à minha disposição mais próximo da leitura por mim feita do modelo da geração, como sistema de gerenciamento dos avanços da China por muitas décadas futuras.

2 A análise das relações políticas entre os dirigentes chineses tem tomado vulto, como subárea da disciplina Estudo da China Contemporânea. Há uma grande safra de livros e artigos acadêmicos voltados para o assunto, mas por motivos de ordem prática eu me limitei a três revistas especializadas: The China Quarterly, Asian Survey e The China Journal, além do noticiário da imprensa periódica e da contínua análise jornalística de The Far Eastern Economic Review - FEER, de Hong Kong. The China Journal (anteriormente The Australian Journal of Chinese Affairs), órgão do Centro da China contemporânea da Universidade Nacional da Austrália, dedicou dois números (34, julho de 1995, e 45, janeiro de 2001) a um debate entre grandes nomes da sinologia sobre a evolução da política de elite na China. Os textos correspondentes muito me ajudaram a entender o modelo chinês da geração. Para a ascensão dos tecnocratas, cf: Xiaowei Zang, "The Fourteenth Central Committee of the CCP: Technocracy or Political Technocracy?”, in Asian Survey, vol XXXVIII/3, March 1998.

$4 \quad$ Li Cheng e Lynn White, “The Army in the Succession to Deng Xiaoping”, in Asian Survey, vol XXXIII/8, Aug. 1993.

5 Cf. Li Cheng, "University Networks and the Rise of Qinghua Graduates in China’s Leadership”, in The Australian Journal of Chinese Affairs, n. 32 July 1994.

6 Cong Cao e Richard P. Suttmeier, “China’s Brain Bank - Leadership and Elitism in Chinese Science and Engineering”, in Asian Survey, vol XXXIX/3, May/June 1999, p. 525. Suttmeier acompanha as atividades científicas na China desde a época da Mao Zedong, sendo possível encontrar textos seus em The China Quarterly e Asian Survey da década dos 1970. É dele um dos primeiros estudos sobre o assunto após o deslanchamento das reformas modernizadoras de Deng Xiaoping: "Reform, Modernization, and the Changing Constitution of Science in China”, in Asian Survey, vol XXXIX/10, Oct. 1989. Foi chamado para escrever um dos capítulos da seção C\&T, na coletânea “China’s Economic Dilemmas in the 1900s”, organizada 
pelo Joint Economic Committee do Congresso dos Estados Unidos, em 1993.

7 Para a trajetória partidária de Jiang Zemin e sua história pessoal v. no n. 45 de The China Journal (jan. 2001), os artigos: Lowell Dittmer, "The Changing Nature of Elite Power Politics”; Frederick C. Teiwes, "Normal Politics with Chinese Characteristics”; David Shambaugh, “The Dynamics of Elite Politics During the Jiang Era”.

8 Jeremy Paltiel, “Jiang Talks Politics - Who Listens? Institutionalization and Its Limits in Market Leninism”, in The China Journal, n. 45 (Jan. 2001), fornece boas indicações sobre como Deng Xiaoping visualizava o papel das gerações e seu respectivo núcleo na legitimação continuada do PCC.

9 Para as trajetórias pessoal e profissional de Hu Jintao, cf.: You Ji, “The Heir Apparent”, in The China Journal, n 48 (Jul. 2002); Richard Daniel Ewing, "Hu Jintao. The Making of a Chinese General Secretary”, in The China Quarterly, n. 173 (March. 2003).

10 Sobre Zeng Qinghong, v. Susan V. Lawrence, “Make Room at the Top”, in FEER (18.04.02).

11 V. You Ji, “Jiang Zemins' Command of the Military”, in The China Journal, n. 45 (Jan. 2001).

12 Susan V. Lawrence, “Wen Jiabao Is No New Zhu”, FEER (14.03.02).

13 Sobre o ambiente político do XV Congresso e as modificações econômicas e de pessoal nele aprovadas, v. Richard Baum, “The Fifteenth National Party Congress”: Jiang Takes Command, in The China Quarterly, n. 153 (1998).

14 Para uma análise abrangente e bem informada do programa de Zhu Rongji v. David Zweig, “China’s Stalled Fifth Wave: Zhu Rongji’s Reform Package of 1998-2000", in Asian Survey, XLI/2 (March/April 2002; também Xiaobo Hu, “The State, Enterprises, and Soiety in PostDeng china”, in Asian Survey, XL/4 (July/Aug. 2000). Sobre a novela do ingresso da China na OMC, desde o tempo do GATT, v. matéria especial de The Economist (20.11.99); também Susan V. Lawrence, “Jiang’s Two Faces”, in FEER (02.12.95).

15 Para o fundo de cena da preparação do XVI Congresso (2002); do lançamento das "Três Representações”; e da aceitaçÃo de empresários no PCC, v: Susan V. Lawrence, "Three Cheers for the Party”, FEER (26.10.00); Bruce Gilley, “Jiang's Turn Temptf Fate”, FEER (30.08.01); Sesan V. Lawrence, “Jiang Ensures Party Endures”, FEER (21.11.02); James Kynge, “It Is a Glorious Thing to Join the Party”, Financial Times (06.11.02).

16 Para uma abrangente análise do XVI Congresso, v. Joseph Fewsmith, “The Sixteenth National Party Congress: The Succession That Didn’t Happen”, in The China Quarterly, n. 173 (March 2003)

17 V. Andrew J. Nathan e Bruce Gilley, “Os Novos Dirigentes da China” in Política Externa (São Paulo: Paz \& Terra) 11/4 (março-abril-maio 2003).

18 A referência, aqui, é ao livro China Since Tiananmen: The Politics of Transition. New York: Cambridge University Press, 2001. Fewswith tem vários outros livros sobre o tema e um importante artigo: “The New Shape of Elite Politics”, in The China Journal, n. 45 (Jan. 2001).

19 Manuel Castells, A Era da Informação. Vol 3, Fim de Milênio. São Paulo: Paz \& Terra, 1999, p. 348-373.

\section{Resumo}

O presente artigo examina, à luz da mudança de líderes na China, por ocasião do XVI Congresso do PCC (novembro de 2002), a utilização pelos dirigentes chineses da categoria sociológica da "geração" como forma de 
sistematizar e regulamentar as transições de poder no país, e de assegurar a legitimação permanente do atual regime. Ênfase é dada à figura do "núcleo de geração".

\section{Abstract}

Starting from the leadership change in China, on the occasion of the $16^{\text {th }}$ Congress of the CCP (November 2002), the present article analyses the utilization of the concept of "generation", a sociological category, as the way to systematize and regulate the transitions of power in China, assuring at the same time the permanent legitimization of the regime. Special attention is given to the man at the center of each generation.

Palavras-chave: Governança da China; Encadeamento de gerações; Política de elite; O núcleo da geração.

Keywords: China's government; Generational succecion; Elite politics; The man at the center. 